\title{
Multifunctional Roles for the N-Terminal Basic Motif of Alfalfa mosaic virus Coat Protein: Nucleolar/Cytoplasmic Shuttling, Modulation of RNA-Binding Activity, and Virion Formation
}

\author{
Mari Carmen Herranz, Vicente Pallas, and Frederic Aparicio \\ Department of Molecular and Evolutionary Plant Virology, Instituto de Biología Molecular y Celular de Plantas (UPV-CSIC), \\ Ingeniero Fausto Elio s/n, 46022 Valencia, Spain
}

Submitted 3 April 2012. Accepted 12 April 2012.

\begin{abstract}
In addition to virion formation, the coat protein (CP) of Alfalfa mosaic virus (AMV) is involved in the regulation of replication and translation of viral RNAs, and in cell-tocell and systemic movement of the virus. An intriguing feature of the AMV CP is its nuclear and nucleolar accumulation. Here, we identify an N-terminal lysine-rich nucleolar localization signal (NoLS) in the AMV CP required to both enter the nucleus and accumulate in the nucleolus of infected cells, and a C-terminal leucine-rich domain which might function as a nuclear export signal. Moreover, we demonstrate that AMV CP interacts with importin- $\alpha$, a component of the classical nuclear import pathway. A mutant AMV RNA 3 unable to target the nucleolus exhibited reduced plus-strand RNA synthesis and cell-to-cell spread. Moreover, virion formation and systemic movement were completely abolished in plants infected with this mutant. In vitro analysis demonstrated that specific lysine residues within the NoLS are also involved in modulating CP-RNA binding and CP dimerization, suggesting that the NoLS represents a multifunctional domain within the AMV CP. The observation that nuclear and nucleolar import signals mask RNA-binding properties of AMV CP, essential for viral replication and translation, supports a model in which viral expression is carefully modulated by a cytoplasmic/ nuclear balance of $\mathrm{CP}$ accumulation.
\end{abstract}

In recent years, increasing evidence has been found showing that coat proteins $(\mathrm{CP})$ of plant viruses actively participate in diverse roles of the viral infection process, from acting as an active subunit of the replication complex to permitting cell-tocell and systemic movement and plant-to-plant transmission or suppressing the immune response of the plant host (Asurmendi et al. 2004; Bol 2005; Csorba et al. 2009; Kao et al. 2011; Pallas and Garcia 2011; Reichert et al. 2007; Scholthof 2005).

Alfalfa mosaic virus (AMV) is the only member of the genus Alfamovirus in the family Bromoviridae. The AMV genome consists of three single-stranded RNAs of plus sense polarity. RNA 1 and RNA 2 encode the replicase subunits P1 and P2, respectively, whereas RNA 3 encodes the movement protein (MP) and serves as a template for the synthesis of the nonrep-

Corresponding author: F. Aparicio; E-mail: faparici@ibmcp.upv.es

* The $\boldsymbol{e}$-Xtra logo stands for "electronic extra" and indicates that five supplementary figures and one supplementary table are published online. licating subgenomic RNA 4 (sgRNA 4), which encodes the CP (Bol 2005). Alfamovirus and the closely related genus Ilarvirus (Sanchez-Navarro and Pallas 1997) are unique among the plant viruses in requiring the presence of the $\mathrm{CP}$ in the inoculum to initiate the infection in a phenomenon termed "genome activation". This is a process by which a few molecules of CP bind to the 3-nontranslated region (3-NTR) of its genomic RNAs to initiate and maintain the viral infection (Bol 2005).

The AMV CP is a multifunctional protein required for diverse processes during infection (Bol 2005). Thus, the CP is an integral component of the viral replicase complex essential for the regulation of viral replication (Quadt et al. 1991). Consistently, plus-strand RNA 3 synthesis was shown to be severely reduced in transgenic Nicotiana tabacum plants expressing the AMV $\mathrm{P} 1$ and P2 proteins (P12 plants) (Taschner et al. 1991) in the absence of CP (Van der Vossen et al. 1994). The 3-NTR of all three genomic AMV RNAs are highly conserved and contain several CP binding sites. Binding of the CP to these 3-NTR organizes the 3 '-terminal RNAs to permit the correct positioning of the replicase complex at the initiation site for minus-strand RNA synthesis (Reichert et al. 2007). In fact, recent evidences suggest that the concentration of $\mathrm{CP}$ constitutes a mechanism for the regulation of virus replication (Guogas et al. 2005). Moreover, the CP stimulates sgRNA 4 synthesis (De Graaff et al. 1995). Binding of the CP to the 3-NTR also enhances translation of viral RNAs by mimicking the function of the host poly(A)-binding protein (Krab et al. 2005; Neeleman et al. 2004). It is well established that RNA-binding properties of the $\mathrm{CP}$ reside within the first 25 amino acids of the protein, being the arginine at position 17 (R17) critical for RNA binding and establishment of AMV infection (Ansel-McKinney et al. 1996). In addition, apart from its role in replication and encapsidation, the $\mathrm{CP}$ is also required for cell-to-cell movement. (Sanchez-Navarro and Bol 2001; Tenllado and Bol 2000; Van der Vossen et al. 1994). Previous mutational analysis suggested that different domains within the $\mathrm{CP}$ are involved in mediating the different functions of the protein during infection (Tenllado and Bol 2000).

Early electron microscopic studies showed that the AMV CP accumulated in the cytoplasm and nucleus and around the nucleolus of infected cells (Vanpeltheerschap et al. 1987). Later, fluorescent-protein-tagged AMV CP revealed CP localization in the cytoplasm and at tubular structures formed by polymerization of the MP (Sanchez-Navarro and Bol 2001). The nucleolus has been recently identified as an important compartment during the infection cycle of both plant and animal viruses 
(Greco 2009; Taliansky et al. 2010). The nucleolus is a multifunctional nuclear structure playing roles in various cellular processes, including ribosome and ribonucleoprotein particle biogenesis, cell cycle regulation, stress response, tRNA precursor processing, and gene silencing. Several single-stranded DNA, negative and positive single-stranded RNA, and RNA reverse-transcribing viruses encode proteins which target the nucleolus (Taliansky et al. 2010). Among those proteins are the $\mathrm{CP}$ of Potato leafroll virus (PLRV), Satellite panicum mosaic virus (SPMV), and Ourmia melon virus (Crivelli et al. 2011; Haupt et al. 2005; Qi et al. 2008). Thus, nucleolar targeting appears to be a general feature of viral proteins. However, despite the apparent importance of the nucleolus for infection, the functional significance of nucleolar accumulation of viral proteins remains to be elucidated in most cases.

In the present work, we determined motifs responsible for trafficking of the AMV CP into and out of the nucleus. We identified an N-terminal lysine-rich nucleolar localization signal (NoLS) required for both entry and accumulation in the nucleolus of infected cells. In addition, we defined a C-terminal leucine-rich domain which might function as a nuclear export signal (NES). Inoculation of P12 plants with an infectious AMV RNA 3, in which the NoLS was mutated, revealed severely impaired plus-strand RNA synthesis and cell-to-cell movement. In addition, virion formation and systemic movement were completely abolished in those plants. Our data suggest an implication of lysine $(\mathrm{K})$ residues within the NoLS in CP-RNA binding and CP dimerization. Overall, our results indicate that the AMV CP NoLS is a multifunctional domain important for nucleolar/cytoplasmic shuttling, modulation of RNA-binding activity of CP, and virion formation.

\section{RESULTS}

\section{AMV green fluorescent protein $\mathrm{CP}$ accumulates} in the nucleolus of infected cells.

To determine the subcellular localization of AMV CP in infected cells, we used AMV RNA 3 clones that express either the free green fluorescent protein (GFP) or the CP fused to the C-terminal part of the GFP, together with the MP and wild-type (wt) CP (Sanchez-Navarro and Bol 2001; SanchezNavarro et al. 2001) (Fig. 1A, R3 GFP:CP and R3 GFP constructs, respectively). Confocal laser-scanning microscopy (CLSM) analysis of P12 plants inoculated with R3 GFP:CP transcripts revealed that GFP:CP accumulated in the cytoplasm (not shown), nucleus, and nucleolus of infected cells (Fig. 1A, lower panel, left), whereas the expression of free GFP from the R3 GFP transcripts rendered a nucleoplasmic localization without specific association with the nucleolus (Fig. 1A, upper panel, left). To confirm the nucleolar localization of AMV CP, P12 plants inoculated with either RNA transcripts of R3 GFP or R3 GFP:CP were agroinfiltrated with a binary plasmid expressing the Arabidopsis thaliana fibrillarin-2 fused to the monomeric red fluorescent protein (35S:AtFib2-mRFP). Perfect co-localization of GFP:CP and the nucleolar marker confirmed CP localization to the nucleolus (Fig. 1A, lower panel, right). Expression of 35S:AtFib2mRFP in R3 GFP-infected cells did not reveal co-localization of GFP and RFP fluorescence in the nucleolus (Fig. 1A, upper panel, right). In order to investigate whether any other viral-encoded protein was required for the nucleolar localization of the CP, GFP:CP was transiently expressed by agroinfiltration in $N$. benthamiana and $N$. tabacum (both wt and P12 plants). In this case, the fluorescence remained extremely weak and restricted to the nucleoplasm. However, co-agroinfiltration of CP:GFP with the silencing suppressor HCPro of Potato virus $Y$ (PVY) led to nucleolar accumulation levels of the viral protein comparable with those obtained upon infection (data not shown). This indicates that no other viral-encoded protein is required for nucleolar localization of $\mathrm{CP}$ and that the protein presumably needs to accumulate to a certain threshold concentration to be detected in the nucleolus.

\section{Two domains located at the $\mathrm{N}$ - and $\mathrm{C}$-terminal ends of AMV CP are involved in its nuclear import and export, respectively.}

Most motives identified as necessary to target a protein to the nucleolus consist of short sequences ( 7 to 30 residues) characterized by the presence of several basic residues (Krichevsky et al. 2006). The N-terminal region of the AMV $\mathrm{CP}$ contains a stretch of basic residues resembling a putative nuclear localization signal (NLS) or NoLS (Fig. 1B). Deletion of the first $27 \mathrm{~N}$-terminal amino acids of the protein abolished nuclear localization of GFP:CP (Fig. 1B, R3 GFP:CP $\triangle N 27$ construct) whereas the GFP fused to the first $30 \mathrm{~N}$-terminal residues of the $\mathrm{CP}$ was able to enter the nucleus and accumulate in the nucleolus (Fig. 1B, R3 GFP:CPN30). These results demonstrated that the $\mathrm{N}$-terminal basic region of the $\mathrm{CP}$ is sufficient for nuclear and nucleolar targeting of AMV CP. To identify critical residues within this domain, we synthesized RNA 3 variants with alanine (A) substitutions at specific basic residues of the R3 GFP:CP construct. After inoculation in P12 plants, we found that the change of $\mathrm{K}$ for $\mathrm{A}$ residues at positions 5, 6, 10, and 13 restricted the transport of the $\mathrm{CP}$ to the nucleolus and increased its accumulation at the nuclear periphery (Fig. 1B, R3 GFP:CP [K5-13:A] construct). In contrast, R3 GFP:CP(K16, R17:A) and R3 GFP:CP(R24, K25:A) constructs, in which the basic amino acids $\mathrm{K}$ and arginine at positions 16 , 17 and 25, 26 respectively, were replaced by A, rendered mutant proteins that retained the nucleolar localization (Fig. 1B). Western blot analysis using an anti-GFP antibody confirmed that all GFP fusions were expressed from the corresponding R3 transcripts (Fig. 1C). These results indicated that the 5-KKAGGK AGK-13 sequence operates as an NLS and NoLS. In particular, the $\mathrm{K}$ residues at positions $5,6,10$, and 13 appear to be required for entry into the nucleus and nucleolar targeting.

Transport into and out of the nucleus requires that nucleartrafficking proteins also contain an NES, which are short hydrophobic sequences rich in leucine residues (Krichevsky et al. 2006; La Cour et al. 2003). To determine whether a leucinerich motif at the C-terminus of AMV CP (Fig. 1D, underlined) was implicated in nuclear export, a deletion mutant lacking the 204-LRSLIVGLF-212 sequence was generated (Fig. 1D, R3 GFP:CP $\triangle N E S$ construct). Cells infected with R3 GFP:CP $\triangle N E S$ clearly exhibited higher fluorescence in the nucleus compared with the R3 GFP:CP control (Fig. 1D). In order to quantify this observation, images of 100 nuclei infected with each construct were taken and nuclear fluorescence measured using Image $\mathbf{J}$ software (W. Rasband, National Institutes of Health, Bethesda, MD, U.S.A.). Fluorescence intensities corresponding to either GFP:CP or GFP:CPANES protein accumulation were normalized to the nucleus area, yielding fluorescence intensity units. The graph in Figure 1D shows the percentage of nuclei with fluorescence intensity of 50 to 150 and 150 to 250 intensity units. We found that only $35.3 \%$ of nuclei of cells infected with R3 GFP:CP exhibited a relative intensity of 150 to 250 units whereas this percentage increased to $54.2 \%$ in cells infected with R3 GFP:CP $\triangle$ NES. This suggests that the motif 204-LRSLIVGLF-212 might represent an NES. Interestingly, most nuclei of R3 GFP:CPANES-infected cells displayed a nucleoplasmic pattern with empty nucleoli (Supplementary Fig. S1), suggesting that the motif 204-LRSLIVGLF-212 may also be implicated in the nucleolar accumulation of AMV CP during infection. 

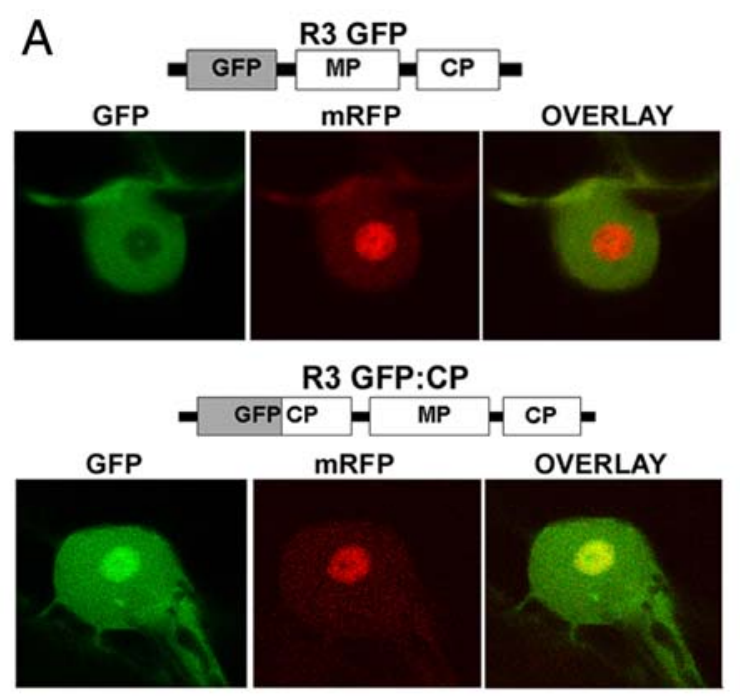

D

\section{2 \\ GPLRSLITVGLFDEADDLDRH}
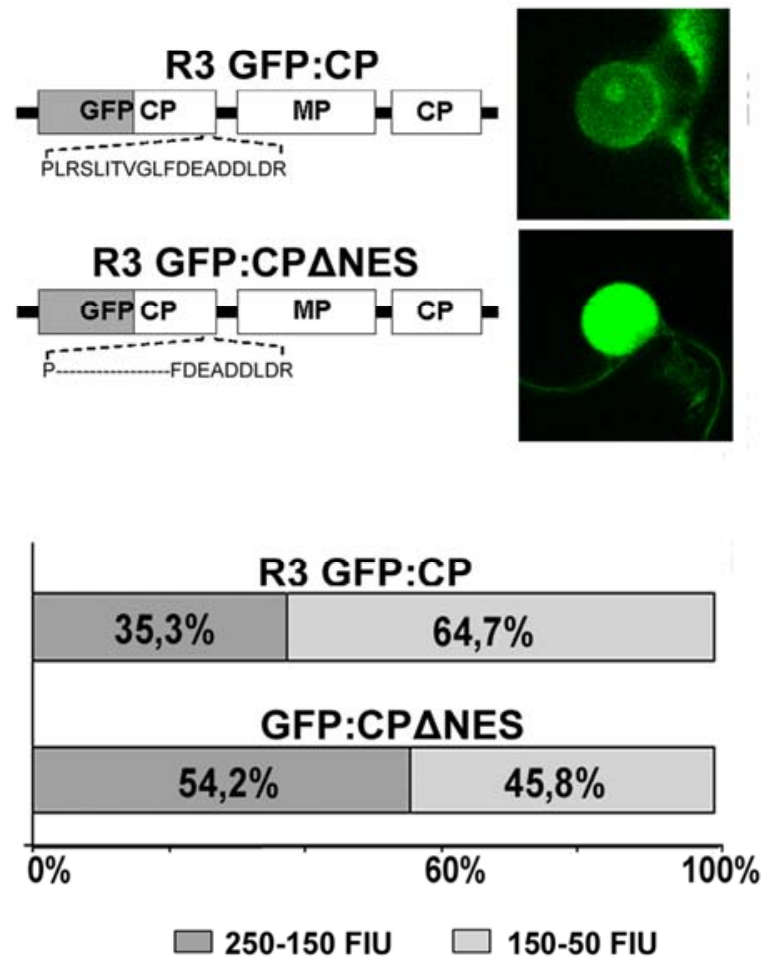

B MSSSQ $\stackrel{5}{1} \quad \stackrel{17}{17} \quad r$

R3 GFP:CPAN27

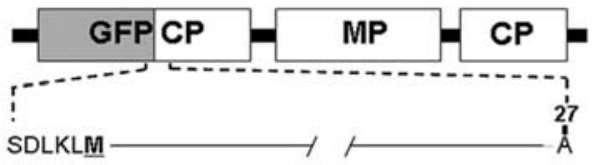

R3 GFP:CPN30

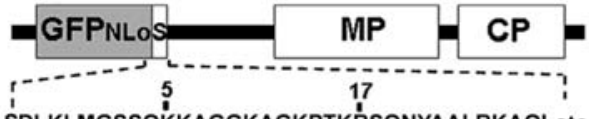

SDLKLMGSSQKKAGGKAGKPTKR'SQNYAALRKAQLstop

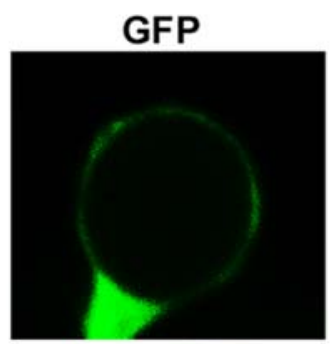

R3 GFP:CP(K5-13:A)

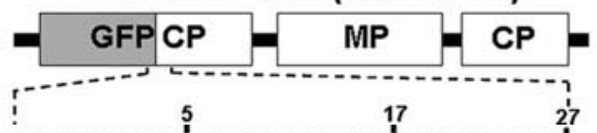

SDLKLMGSSQÁAAGGAAGAPTK'RSQNYAALRKA்

R3 GFP:CP(K16,R17:A)

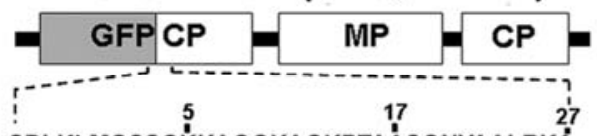
SDLKLMGSSQḰKKAGGKAGKPTAẢSQNYAALRKÁ

R3 GFP:CP(R25,K26:A)

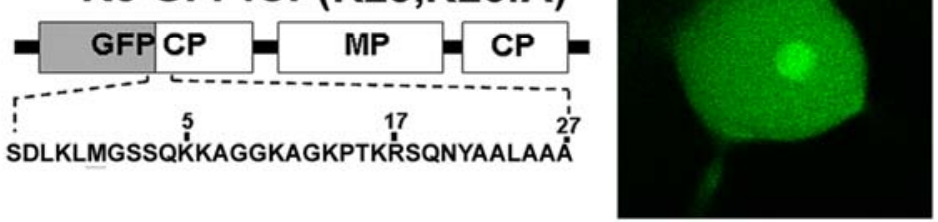

C

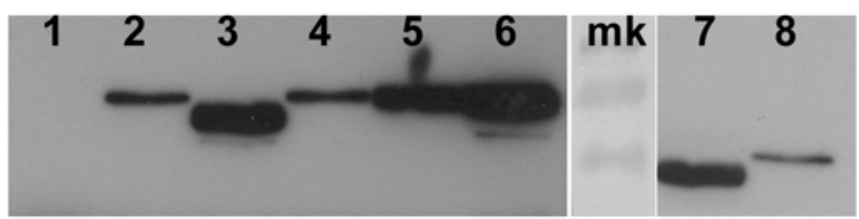

Fig. 1. Nuclear and nucleolar accumulation of Alfalfa mosaic virus (AMV) coat protein (CP) in infected cells. A, Confocal laser-scanning microscopy (CLSM) images of single nuclei of P12 cells infected with AMV RNA 3 transcripts expressing either green fluorescent protein (GFP) alone (R3 GFP) or the GFP:CP fusion protein (R3 GFP:CP) and co-agroinfiltrated with the Arabidopsis thaliana fibrilarin-2 fused to the monomeric red fluorescent protein (mRFP). B, Amino acid sequence of the N-terminal 27 residues of AMV CP. Basic residues are indicated in bold. Representative CLSM images of single nuclei of P12 cells infected with AMV RNA 3 carrying different GFP:CP versions are shown. C, Western blot detection of the GFP-fusion proteins expressed by each construct. Lane 1, noninoculated leaf; lane 2, R3 GFP:CP; lane 3, R3 GFP:CP $\Delta \mathrm{N} 27$; lane 4, GFP:CP(K5-13:A); lane 5, R3 GFP: CP(K16,R17:A); lane 6, R3 GFP:CP(R25,K26:A); lane 7, R3 GFP; lane 8, R3 GFP:CPN30; mk, molecular marker. D, Amino acid sequence of the C-terminal 20 residues of AMV CP. The putative nuclear export signal is underlined. Representative images of single nuclei of P12 cells infected with AMV RNA 3 carrying GFP:CP constructs indicated on the left are shown. The graph at the bottom depicts the percentage of nuclei grouped into two different ranges of fluorescence intensity units (FIU). 
AMV CP may use an importin-dependent pathway to enter the nucleus.

Because deletion of the N-terminal basic motif in $\mathrm{CP}$ impaired nuclear accumulation of the protein (Fig. 1B), we wondered whether nuclear import might be mediated by an active mechanism. In Arabidopsis, the most common mechanism for active protein import into the nucleus requires importin- $\alpha$
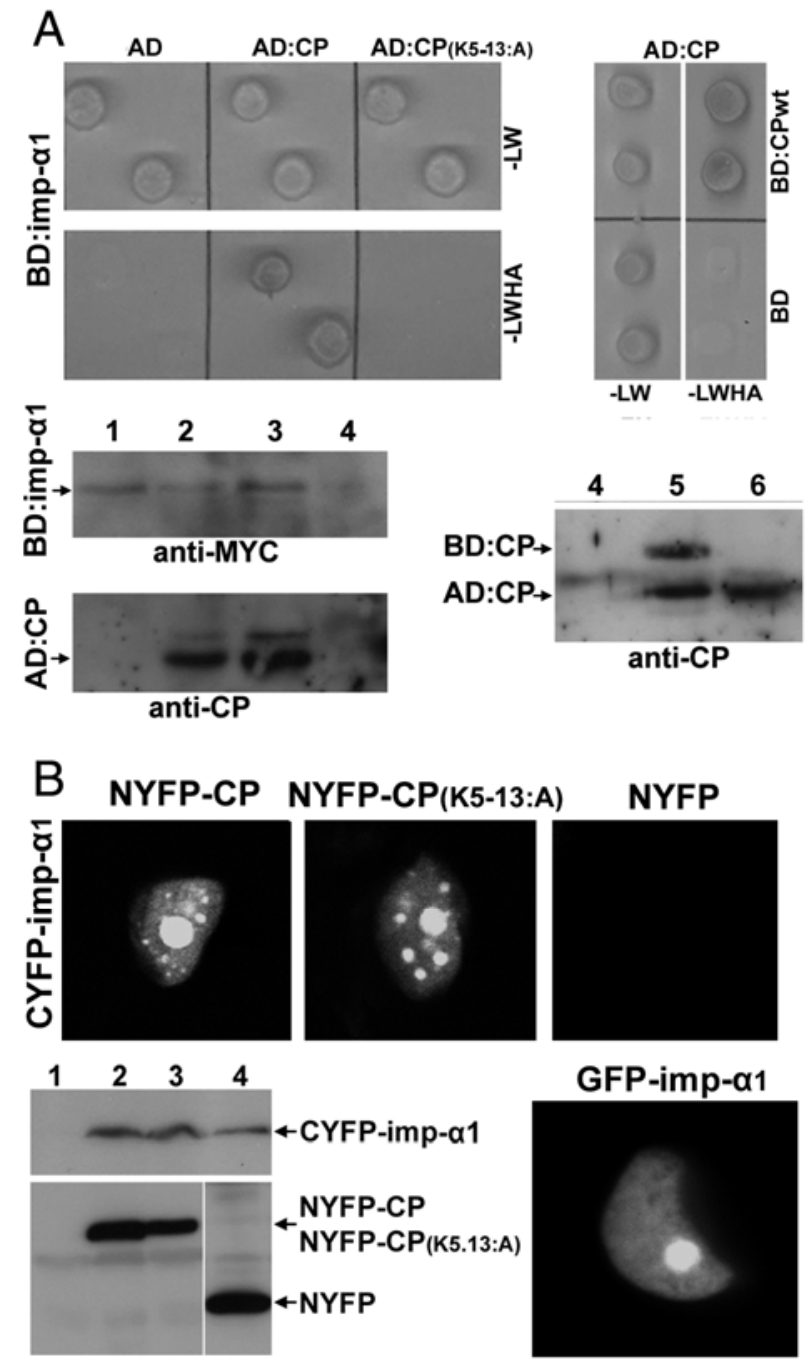

Fig. 2. Study of the interaction between the wild-type and mutant viral coat protein (CP) with Arabidopsis thaliana importin- $\alpha$ isoform 1 (imp- $\alpha 1$ ) by $\mathbf{A}$, yeast two-hybrid and $\mathbf{B}$, bimolecular fluorescent complementation assays. $\mathbf{A}$, To confirm interactions, yeast cells co-transformed with the indicated plasmids were spotted on synthetic minimal medium lacking leucine, tryptophan, histidine and adenine (-LWHA). Self-interaction of CP (binding domain $[\mathrm{BD}]: \mathrm{CP}$-activating domain $[\mathrm{AD}]: \mathrm{CP})$ and empty $\mathrm{BD}$ plasmid plus $\mathrm{AD}: \mathrm{CP}$ interaction (BD-AD:CP) were used as positive and negative controls, respectively. Western blot of total protein yeast extracts with the indicated antibodies confirmed proper expression of the proteins: Lanes 1, 2, and 3, yeast cotransformed with BD:imp- $\alpha 1$ plus empty $\mathrm{AD}, \mathrm{AD}: \mathrm{CP}$, or $\mathrm{AD}: \mathrm{CP}(\mathrm{K} 5-13: \mathrm{A})$ respectively; lane 4, yeast cells co-transformed with empty $\mathrm{BD}$ and $\mathrm{AD}$ plasmids; lanes 5 and 6 , cells expressing $\mathrm{BD}: \mathrm{CP}$ plus $\mathrm{AD}: \mathrm{CP}$ and empty $\mathrm{BD}$ plus $\mathrm{AD}: \mathrm{CP}$, respectively. B, Confocal laser-scanning microscopy images of nuclei from Nicotiana benthamiana leaves co-agroinfiltrated with binary plasmid expressing C-terminal yellow fluorescent protein (CYFP)-imp- $\alpha 1$ plus N-terminal yellow fluorescent protein (NYFP):CP, NYFP:CP(K5-13:A), or NYFP. Fluorescence as a result of the interaction accumulated only in the nucleus and nucleolus of cells co-infiltrated with CYFP-imp- $\alpha 1$ plus NYFP:CP or NYFP:CP(K5-13:A). Green fluorescent protein (GFP)-imp- $\alpha 1$ also accumulated exclusively in the nucleus and nucleolus. Western blot analysis was carried out to specifically detect $\mathrm{N}$ - and C-terminal fusion proteins. Lane 1, noninfiltrated; lane 2, 3, and 4, leaves co-infiltrated with CYFP-imp- $\alpha 1$ plus NYFP, NYFP:CP(K5-13:A), or NYFP:CP, respectively.
(Krichevsky et al. 2006). The Arabidopsis genome contains nine importin- $\alpha$ isoforms (Bhattacharjee et al. 2008). To test a possible role for the importin- $\alpha$ pathway in nuclear trafficking of AMV CP, we investigated direct interaction between isoform 1 (imp- $\alpha 1)$ and both AMV CP and CP(K5-13:A) using yeast two-hybrid $(\mathrm{Y} 2 \mathrm{H})$ assays. The respective $\mathrm{CP}$ and Arabidopsis imp- $\alpha 1$ coding sequences were fused to the activating domain (AD) and the binding domain (BD) of $\mathrm{Y} 2 \mathrm{H}$ plasmids, respectively, transformed into yeast cells, and grown at $28^{\circ} \mathrm{C}$ for 3 days on minimal synthetic dropout selective medium. We found that $\mathrm{CP}$ but neither mutant $\mathrm{CP}(\mathrm{K} 5-13: \mathrm{A})$ nor the empty $\mathrm{AD}$ vector interacted with imp- $\alpha 1$ (Fig. 2A). Previous research established that AMV CP-CP interactions can be revealed by Y2H analyses (Tenllado and Bol 2000). Thus, self-interaction of $\mathrm{CP}$ (BD:CP-AD:CP) and empty BD-AD:CP were used as positive and negative controls, respectively. Consistent with earlier results (Tenllado and Bol 2000), we observed strong CP self-interaction and no growth with BD-AD:CP (Fig. 2A). However, after a longer incubation time at $28^{\circ} \mathrm{C}$ (approximately 6 days), we found that colonies co-transformed with the pair AD:CP(K5-13:A)-BD:imp- $\alpha 1$ and some of the colonies AD-BD:imp- $\alpha 1$ started to show a weak growth (Supplementary Fig. S2). These results may indicate that either $\mathrm{CP}(\mathrm{K} 5$ 13:A) also interacts with imp- $\alpha 1$, although with a lower strength, or that imp- $\alpha 1$ weakly interacts with the NLS of SV40 present in the Gal4AD domain of the pGADT7 plasmid, complicating the interpretation of the results. In order to gain more robust evidence of the $\mathrm{CP}-\mathrm{imp}-\alpha 1$ interaction, we used bimolecular complementation analysis (BiFC) as a second validation test (Aparicio et al. 2006). Thus, Arabidopsis imp- $\alpha 1$ fused to the terminal part of the C-terminal yellow fluorescent protein (CYFP) fragment (CYFP-imp- $\alpha 1$ ) was co-agroinfiltrated in $N$. benthamiana leaves with the free $\mathrm{N}$-terminal yellow fluorescent protein (NYFP) fragment or as an N-terminal fusion to the CP (NYFP-CP) and CP(R5-13:A) (NYFP$\mathrm{CP}[\mathrm{R} 5-13: \mathrm{A}])$. YFP fluorescence of epidermal cells was analyzed by CLSM at 2 days postinoculation (dpi). Strong fluorescence concentrated in the nucleus, forming discrete nuclear granules (Fig. 2B). Interestingly, expression of CYFP-imp- $\alpha 1$ and NYFP-CP as well as CYFP-imp- $\alpha 1$ and NYFP-CP(R513:A) pairs yielded reconstitution of YFP fluorescence in the nucleolus. This suggests specific interactions among these pairs of proteins. No fluorescence was detected when CYFPimp- $\alpha 1$ was co-agroinfiltrated with NYFP. To confirm that nuclear and nucleolar localization was typical for imp- $\alpha 1$, the protein was fused to GFP at either its $\mathrm{N}$ - or C-terminal end. After expression by agroinfiltration, both fusion proteins showed the same nuclear or nucleolar localization pattern (Fig. 2B, panel GFP-imp- $\alpha 1$ ). Finally, Western blot analysis of the samples derived from $\mathrm{Y} 2 \mathrm{H}$ and $\mathrm{BiFC}$ experiments revealed that all proteins accumulated at their expected size (Fig. 2A and B). Thus, our results provide circumstantial evidence that the AMV CP uses an importin-dependent pathway to enter the nucleus and that residues in addition to the basic residues in the 5-KKAGGKAGK-13 sequence are important for this interaction.

\section{Mutations in the basic motif in CP impair RNA 3 replication.}

In order to study the relevance of the basic NoLS in the viral context, we replaced the CP wt of the infectious AMV RNA 3 clone by CP(K5-13:A) (Fig. 3A, R3 CP and R3 CP[K5-13:A] constructs, respectively). First, we tested whether the inability of the mutant $\mathrm{CP}$ to target the nucleolus affected the early steps of viral replication by inoculating transcripts of both constructs into P12 protoplasts. In contrast to nontransgenic plants, P12 plants or protoplasts do not require the presence of 
$\mathrm{CP}$ in the inoculum (Taschner et al. 1991). Accumulation of both RNA 3 and sgRNA 4 was detected in total RNA extracts $24 \mathrm{~h}$ postinoculation (hpi) by Northern blot analysis using a digoxigenin-labeled AMV CP probe (DIG-CP), confirming that $\mathrm{R} 3 \mathrm{CP}(\mathrm{K} 5-13: \mathrm{A})$ replicated in $\mathrm{P} 12$ protoplasts. Interestingly, in contrast to R3 CP, sgRNA 4 overaccumulated in R3 CP(K5-13:A)-transfected protoplasts at 24 hpi (Fig. 3B, compare lane 1 and 2). Some RNA 3 degradation products were detected in addition to the RNA 3 and sgRNA 4 (Van der Vossen et al. 1994) (Fig. 3B and D, asterisk). Furthermore, Western blot analysis revealed that the $\mathrm{CP}$ accumulated to higher levels in R3 CP(K5-13:A)-infected protoplasts compared with the control (Fig. 3C, compare lanes 1 and 2).

To analyze the kinetics of viral replication over time, R3 CP and R3 CP(K5-13:A) transcripts were inoculated in P12 plants and total RNA extracts from plants at 2, 3, 4, and 6 dpi were analyzed by Northern blot. Mutant RNA 3 accumulation was hardly detected at all time points (Fig. 3D). Mutant sgRNA 4 was not detected until 4 dpi and reached R3 CP levels at 6 dpi. Consistently, Western blot analysis to detect $\mathrm{CP}$ showed a faint signal for mutant $\mathrm{CP}$ at 2 and 3 dpi whereas $\mathrm{CP}$ accumulated to R3 CP levels at 4 and 6 dpi (Fig. 3E).

Taken together, Northern blot results of protoplasts and plants indicated that mutations in the $\mathrm{CP}$ that blocked nuclear and nucleolar accumulation of the protein caused downregulation of RNA 3 synthesis and a delay in the sgRNA 4 synthesis. Moreover, $\mathrm{CP}$ accumulation was only restored at $4 \mathrm{dpi}$.

An altered silencing suppression activity of the CP(K513:A) in P12 plants may explain these findings. However, si-
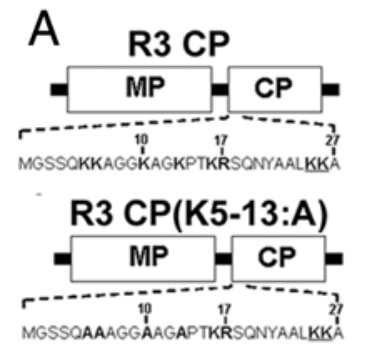

D

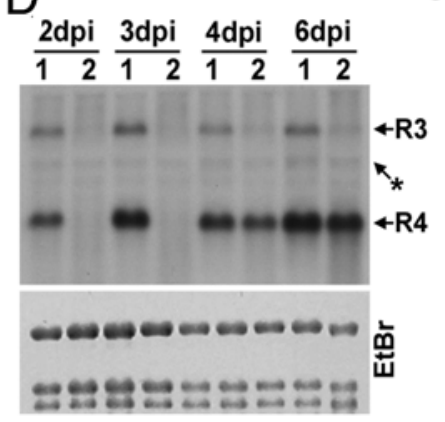

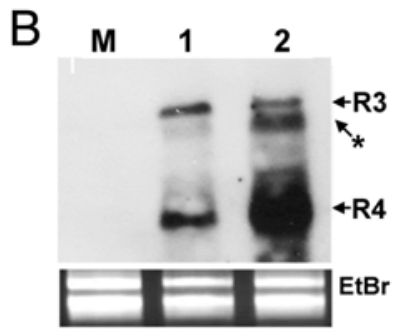

C
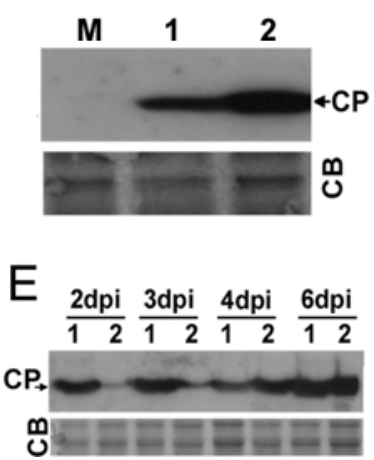

Fig. 3. Time-course analysis of viral RNA and coat protein (CP) accumulation of P12 protoplasts and plants infected with R3 CP or R3 CP(K5-13:A). A, Diagram of the constructs used in this study. B, Northern blot analysis of total RNA extracted at $24 \mathrm{~h}$ postinfection (hpi) from protoplasts inoculated with buffer (lane M), R3 CP (lane 1), or R3 CP(K5-13:A) (lane 2). RNA 3 and subgenomic RNA (sgRNA) 4 are indicated at the right. C, Western blot of total protein extracts from protoplasts analyzed in B using an anti-CP antibody. D, Northern blot analysis of total RNA extracted at 2, 3, 4, and 6 days postinoculation (dpi) of inoculated leaves with R3 CP (lanes 1) or R3 CP(K5-13:A) (lanes 2) from three plants. RNA 3 and sgRNA 4 are indicated on the right. E, Western blot of total protein extracts from samples analyzed in D. Northern blots were hybridized with an AMV digoxigenin-CP probe. Ethidium bromide (EtBr)- and Coomassie Blue (CB)-stained gels served as loading control in Northern and Western blots. Asterisks denote degradation products of viral RNA 3. lencing suppression activity has never been reported for the AMV CP. Therefore, we decided to examine a potential local RNA-silencing activity of AMV CP by using a co-agroinfiltration assay. Transgenic $N$. benthamiana line $16 \mathrm{c}$ plants (Brigneti et al. 1998) were co-agroinfiltrated with mixtures of Agrobacterium-expressing GFP plus AMV CP, GFP plus empty vector (negative control), or GFP plus the well-characterized silencing suppressor HCPro of PVY (positive control). Northern blot analysis revealed that, after $4 \mathrm{dpi}$, the steadystate levels of GFP mRNA were undetectable in leaves coagroinfiltrated with either GFP and empty vector or GFP and AMV CP (Supplementary Fig. S3A, lanes 1 and 2, respectively), whereas high levels of GFP mRNA accumulated even at 6 dpi in leaves co-agroinfiltrated with GFP and HCPro. This result indicates that $\mathrm{AMV} \mathrm{CP}$, when agroinfiltrated, does not prevent post-transcriptional RNA silencing activity. Western blot using anti-CP antibody confirmed the expression of the protein.

\section{Mutations in the $\mathrm{N}$-terminal basic motif impair RNA 3 cell-to-cell and systemic movement.}

In order to determine whether the delay in sgRNA 4 synthesis and $\mathrm{CP}$ accumulation levels of the $\mathrm{CP}(\mathrm{K} 5-13$ :A) mutant was due to reduced cell-to-cell movement of the virus in P12 plants, we constructed an R3 GFP-MP-CP(K5-13:A) infectious RNA (Fig. 4A, left). After inoculation of P12 plants, infection site size was monitored by fluorescence microscopy and measured over 9 dpi. Infection site sizes were greatly reduced in R3 GFP-MP-CP(K513:A)-infected plants compared those in R3 GFP-MP-CP control plants (Fig. 4A). Moreover, fluorescence was detected only from 5 dpi onward in R3 GFP-MP-CP(K5-13:A)-infected plants. These data may indicate that cell-to-cell movement of the mutant virus was compromised.

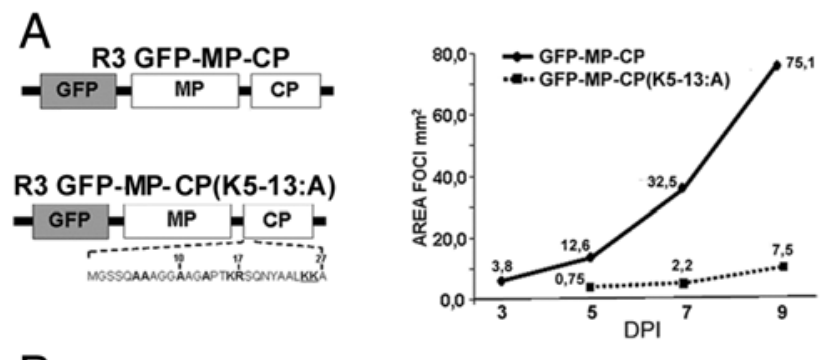

B

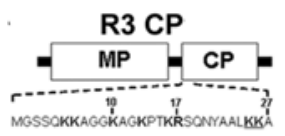

R3 CP(K5-13:A)
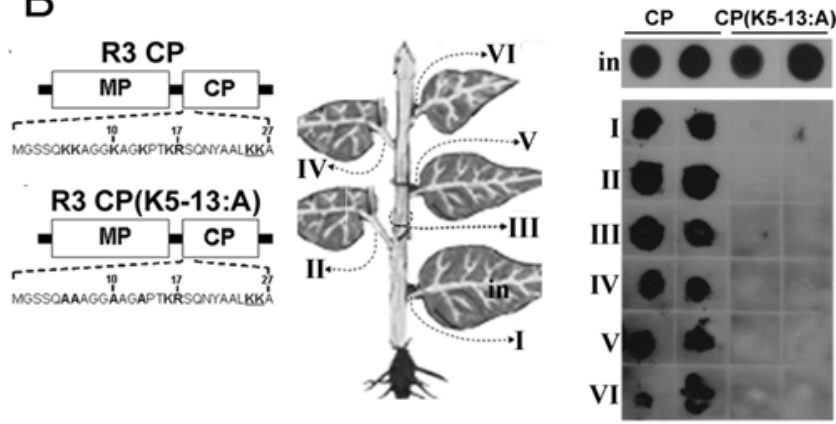

Fig. 4. Effects of the coat protein (CP) (K5-13:A) mutation on viral replication and cell-to-cell movement in P12 plants. A, Left, diagram illustrates constructs used to measure cell-to-cell movement. Right, graph depicts infection site sizes of both RNA 3 constructs measured in inoculated leaves from three different P12 plants over 9 days postinoculation (dpi). B, Left, diagram illustrates the constructs used to measure systemic movement. Right, blot shows detection of viral RNAs. Membranes contained total RNA extracts from inoculated leaves (indicated as "in", central figure) and sap extracts of freshly cut petioles of indicated leaves (I to VI, central figure) from two P12 plants inoculated with R3 CP or R3 CP(K5-13:A) transcripts. Membranes were hybridized with an Alfalfa mosaic virus digoxigenin-CP probe. 
We further analyzed the systemic movement of the $\mathrm{CP}(\mathrm{K} 5$ 13:A) mutant RNA 3. CP and $\mathrm{CP}(\mathrm{K} 5-13: \mathrm{A})$ RNA 3 transcripts (Fig. 4B) were inoculated into a single leaf of P12 plants, and petioles of inoculated (Fig. 4B, leaf I) and upper noninoculated leaves (Fig. 4B, leaves II to VI) were transversely cut and the fresh cuts pressed onto nylon membranes $10 \mathrm{dpi}$. To confirm that all inoculated leaves were infected with AMV, total RNA extracts of these leaves were also directly applied to nylon membranes (Fig. 4B, "in"). Hybridization with a DIG-CP-specific probe revealed that $\mathrm{R} 3 \mathrm{CP}$ accumulated in petioles of all leaves, indicating that it had moved systemically throughout the whole plant (Fig. 4B, blot CP). By contrast, in R3 CP(K513:A)-inoculated plants, all petioles were free of AMV RNA although the inoculated leaf was infected, indicating that the mutant failed to exit from the inoculated leaf and to move systemically (Fig. 4B, blot CP[K5-13:A]).

\section{The K5-13: A mutation within the N-terminal basic motif of AMV CP impairs RNA binding and virion formation.}

Taken together, our results indicated that disruption of the NoLS within the AMV CP abolished its nuclear and nucleolar accumulation, deregulated viral RNA and CP synthesis, decreased cell-to-cell movement, and blocked systemic movement. Therefore, we wondered whether all these defects in the AMV infection cycle were exclusively linked to the inability of the protein to reach the nucleolus or whether other functions of the protein were affected by the $\mathrm{CP}(\mathrm{K} 5-13: \mathrm{A})$ mutation. Binding of the CP to the 5- and 3-NTR of genomic AMV RNAs is necessary to regulate plus- and minus-strand synthesis and translation of viral proteins (Krab et al. 2005; Neeleman et al. 2004). Moreover, it is well established that RNA-binding properties of the $\mathrm{CP}$ reside within the $25 \mathrm{~N}$-terminal amino acids of the
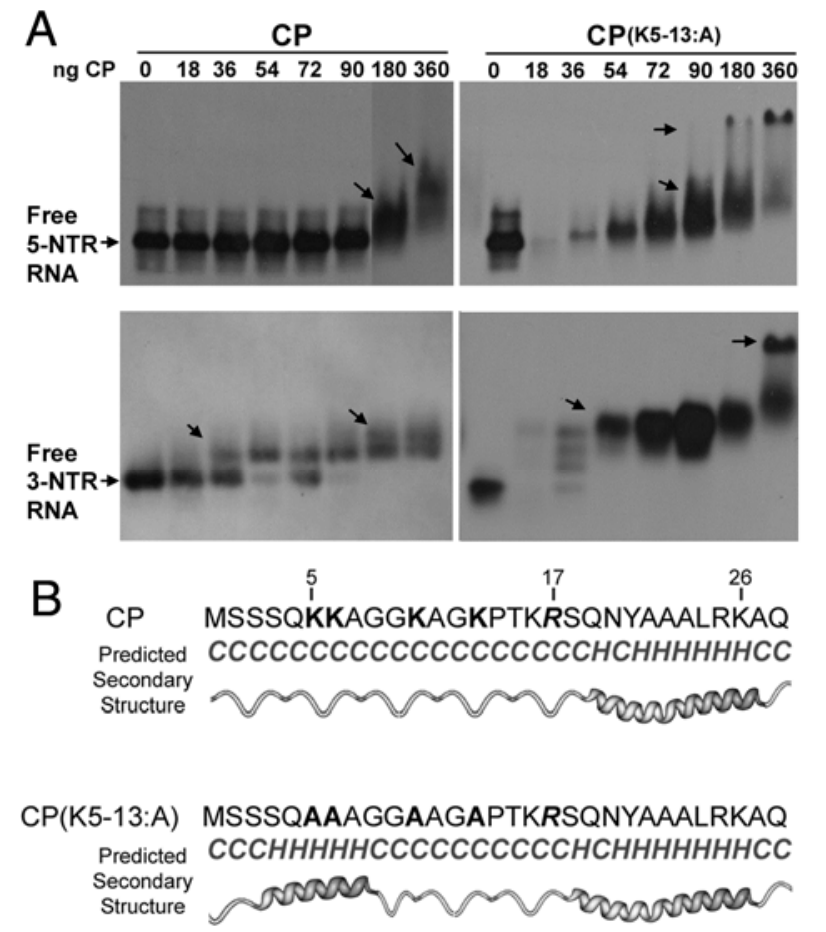

Fig. 5. Effects of the coat protein (CP) (K5-13:A) mutation on RNA binding. A, Electrophoresis mobility shift assays for the binding of CP or $\mathrm{CP}(\mathrm{K} 5-13: \mathrm{A})$ and transcripts corresponding to the 5- and 3-nontranslated region (NTR) of Alfalfa mosaic virus RNA 3. Both RNAs were incubated with increasing amounts of purified $\mathrm{CP}$ or $\mathrm{CP}(\mathrm{K} 5-13: \mathrm{A})$ (indicated in nanograms at the top of the panels). Free RNA and RNA-CP shifted complexes are indicated by arrowheads. B, Predicted secondary structure of the N-terminal 25 residues of $\mathrm{CP}$ and $\mathrm{CP}(\mathrm{K} 5-13: \mathrm{A}) .(\mathrm{C}=$ coiled, $\mathrm{H}=$ helix $)$. protein. In fact, it has been shown that R17 is critical for RNA binding of the CP and establishment of AMV infection (AnselMcKinney et al. 1996; Bol 2005) and that K13 and K16, although not essential, contribute to the full activity of the $\mathrm{CP}$ (Yusibov and Loesch-Fries 1998). Binding of CP and CP(K513:A) to the 5- and 3-NTR of the AMV RNA 3 were analyzed by electrophoretic mobility shift assays (EMSA). After incubation of transcripts with increasing concentrations of purified CP versions, two shifts were detected in both 5- and 3-NTR (Fig. 5A) which, in the case of the 3-NTR, represent intermediate CP-RNA complexes corresponding to the sequential filling of two independent binding sites (Aparicio et al. 2003; Reusken et al. 1994). The first shift in the presence of CP occurred at concentrations of 180 and $36 \mathrm{ng}$ of purified protein with 5-NTR and 3-NTR, respectively (Fig. 5A). The second shift occurred when the protein concentration reached 360 and $180 \mathrm{ng}$, respectively. Unexpectedly, in the presence of CP(K5-13:A), the amount of protein required for both shifts was found to be lower. Indeed, only 18 to $36 \mathrm{ng}$ of protein was required for the first shift whereas the second one required 180 and $360 \mathrm{ng}$ of the mutated CP (Fig. 5A). Free 3-NTR RNA was undetectable in the presence of $90 \mathrm{ng}$ of $\mathrm{CP}$ whereas only $36 \mathrm{ng}$ was required for its mutated form (Fig. 5A). Thus, EMSA experiments indicated that the change of basic $\mathrm{K}$ to neutral $\mathrm{A}$ residues at positions 5, 6, 10, and 13 increased the RNA-binding activity for both 5- and 3-NTR sequences.

In order to analyze whether the amino acid changes in $\mathrm{CP}(\mathrm{K} 5-13: \mathrm{A})$ could result in a structural change in the N-terminal region of $\mathrm{CP}$ which may explain increased binding of
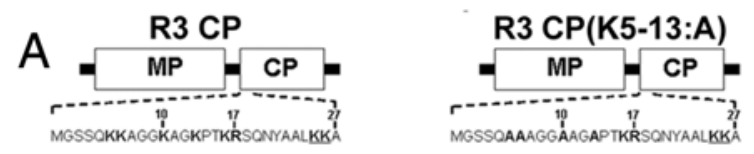

B
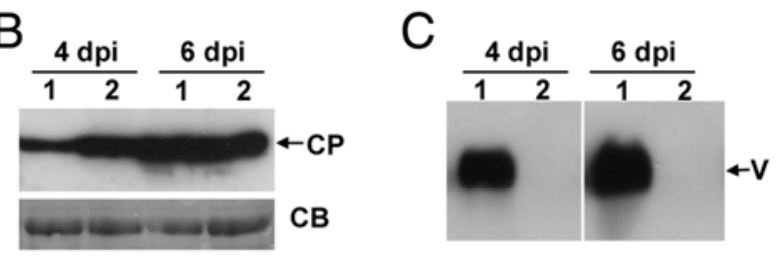

D
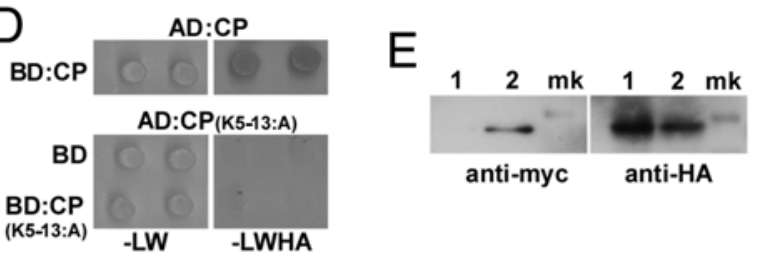

Fig. 6. Analysis of virion accumulation and self-interaction of the coat protein (CP) (K5-13:A) mutant. A, Constructs used to inoculate P12 plants. B, Western blot analysis to detect Alfalfa mosaic virus (AMV)-CP from plants inoculated with R3 CP (lanes 1) or R3 CP(K5-13:A) (lanes 2) at 4 and 6 days postinoculation (dpi). Coomassie Blue (CB)-stained gel served as loading control. C, Northern blot of membranes loaded with homogenates containing virus particles from samples analyzed in B; lanes 1 and 2, plants inoculated with $\mathrm{R} 3 \mathrm{CP}$ and $\mathrm{R} 3 \mathrm{CP}(\mathrm{K} 5-13: \mathrm{A})$, respectively. Northern blot was hybridized with an AMV digoxigenin-CP probe (V, AMV virion). D, Self-interaction of CP(K5-13:A) was analyzed by yeast two-hybrid system. To confirm interactions, yeast cells co-transformed with the indicated plasmids were spotted on synthetic minimal medium lacking leucine, tryptophan, histidine, and adenine (-LWHA). CP self-interaction (AD:CP-BD:CP) was used as positive control. Yeast cells transformed with empty BD plus AD:CP(K5-13:A) did not grow in -LWHA medium. E, Western blot analysis using anti-myc and hemagglutinin (HA) antibodies confirmed proper expression of the proteins; lanes 1 and 2, total protein extracts from yeast transformed with empty BD plus $\mathrm{AD}: \mathrm{CP}(\mathrm{K} 5-13: \mathrm{A})$ and $\mathrm{BD}: \mathrm{CP}(\mathrm{K} 5-13: \mathrm{A})$ plus $\mathrm{AD}: \mathrm{CP}(\mathrm{K} 5-13: \mathrm{A})$, respectively. 
mutant CP to RNA, we used I-TASSER, an online server to predict protein structure and function, (Roy et al. 2010; Zhang 2008). Our secondary structure prediction revealed a capacity of the mutant $\mathrm{CP}$ to form an extra $\alpha$-helix at the $\mathrm{N}$-terminal end of the motif; thus, the R17 previously shown to be essential for RNA binding (Ansel-McKinney et al. 1996) would now be surrounded by two $\alpha$-helixes (Fig. 5B). Hence, our findings suggest a structural change of the protein by mutation of the N-terminal basic amino acids.

Consistently, diverse authors have found that some AMV mutants showing very limited cell-to-cell movement were also defective in encapsidation or CP dimerization (Sanchez-Navarro and Bol 2001; Tenllado and Bol 2000). Low levels of local movement of CP(K5-13:A) prompted us to analyze its capability to self-interact and to form stable viral particles. To investigate encapsidation, P12 plants were inoculated with either R3 CP or R3 CP(K5-13:A) RNA (Fig. 6A). Western blot analyses to detect $\mathrm{CP}$ accumulation in total protein extracts 4 and $6 \mathrm{dpi}$ confirmed that samples were infected (Fig. 6B). In parallel, virions were purified, loaded on agarose gels, and analyzed by Northern blot. We detected viral particles visible as single bands in this assay only with R3 CP-infected samples, indicating that R3 CP(K5-13:A) was unable to encapsidate viral RNA 3 (Fig. 6C, compare lanes 1 and 2). As described above, AMV $\mathrm{CP}-\mathrm{CP}$ interactions can be revealed by $\mathrm{Y} 2 \mathrm{H}$ analyses (Tenllado and Bol 2000). Thus, we used Y2H to test putative self-interaction of $\mathrm{CP}(\mathrm{K} 5-13: \mathrm{A})$ and interaction of $\mathrm{CP}(\mathrm{K} 5$ 13:A) with CP. As expected and previously shown (Tenllado and Bol 2000), CP self-interacted (Fig. 6D, upper panel). By contrast, no self-interaction could be determined with BD:CP(K5-13:A) (Fig. 6D), despite the fact that both fusion proteins were expressed in yeast cells (Fig. 6E, lane 2). Moreover, we did not find interaction between BD:CP-AD:CP(K513:A) (Supplementary Fig. S4). Together, these results indicate that the $\mathrm{K}$ residues in motif 5-KKAGGKAGK-13 are critical to support both $\mathrm{CP}-\mathrm{CP}$ interaction and virus particle formation.

\section{DISCUSSION}

The AMV CP is required to initiate and maintain viral infection and for translation, virion assembly, and cell-to-cell and systemic movement (Bol 2005). The work reported here investigates the function of the N-terminal basic fragment 5-KKA GGKAGK-13 of the AMV CP in these processes. We demonstrate that 5-KKAGGKAGK-13 represents a motif required for i) nuclear and nucleolar localization, ii) modulation of viral RNA binding, and iii) $\mathrm{CP}-\mathrm{CP}$ interaction and virion formation and, consequently, virus movement. The involvement of a specific region in different processes may indicate a regulatory function of this region during infection. This hypothesis is in agreement with the observation that the N-terminal basic RNA-binding domain of Brome mosaic virus $\mathrm{CP}$, which is required to encapsidate viral RNAs (Rao and Grantham 1996), appears to be also implicated in $\mathrm{CP}$ subcellular trafficking to the endoplasmic reticulum (Bamunusinghe et al. 2011). In addition, the N-terminal arginine-rich motif arm of the SPMV CP was shown to be required to bind its cognate RNA and to form virus particles (Qi et al. 2008).

Localization of AMV CP around the nucleolus was previously reported in electron microscopic studies of AMV-infected samples (Vanpeltheerschap et al. 1987). Here, we have mapped a region responsible to target $\mathrm{AMV} \mathrm{CP}$ to the nucleolus. We demonstrate that $\mathrm{N}$-terminal $\mathrm{K}$ residues at positions 5 to 13 within the 5-KKAGGKAGK-13 sequence are essential and sufficient for this transport and define this region as an NoLS of the AMV CP. Although plant viral NoLS are not well characterized, most of the motives that have been identified as necessary for nucleolar targeting are composed of basic amino acid stretches of different length and can, in some cases, overlap with the NLS (Emmott and Hiscox 2009; Taliansky et al. 2010). Furthermore, by $\mathrm{Y} 2 \mathrm{H}$ and $\mathrm{BiFC}$, we have established that the $\mathrm{CP}$ interacts with imp- $\alpha 1$, suggesting that entry into the nucleus may be mediated by an importin-dependent mechanism. These two approaches have been used to analyze the interaction between plant importins and the Arabidopsis lesion-simulating disease resistance 1 (LSD1) gene (He et al. 2011), the virulence protein of Agrobacterium tumefaciens VirD2 (Ballas and Citovsky 1997; Bhattacharjee et al. 2008), the CP of Beet black scorch virus (Zhang et al. 2011), or the 2b protein of $\mathrm{Cu}$ cumber mosaic virus (Wang et al. 2004). Interestingly, CP(K513:A) still interacted with imp- $\alpha 1$ by $\mathrm{BiFC}$ although, in $\mathrm{Y} 2 \mathrm{H}$, the interaction was much weaker. Taken into account that importins interact with NLS (Hübner et al. 1999), our results suggest that the CP of AMV contains separate NLS and NoLS. However, it was recently reported that the Agrobacterium VirD2 protein containing a deletion of the C-terminal bipartite NLS still interacted in $\mathrm{Y} 2 \mathrm{H}$ with imp- $\alpha 4$ (Bhattacharjee et al. 2008). The authors proposed that the C-terminal NLS of VirD2 modulates the strength of interaction with imp- $\alpha 4$ but that additional adjoining residues would be also implicated in the interaction. Thus, we cannot rule out the possibility that NoLS of AMV CP also constitutes at least part of an NLS. Overlap between NoLS and NLS have been previously described for some viral proteins. Examples are the CP of Tomato leaf curl Java virus associated with DNAb satellite (Sharma and Ikegami 2009) and the nonstructural open reading frame (ORF) 57 protein of Herpesvirus (Boyne and Whitehouse 2006).On the other hand, we found that Arabidopsis imp- $\alpha 1$ fused to the GFP localized to the nucleus and clearly accumulated in the nucleolus. Moreover, the nucleolus seemed to increase in size and, in some cases, inclusions in the nucleoplasm were detected, which we interpret as a consequence of the over-expression of the protein inherent to the agroinfiltration approach. Increase of the nucleolus size and appearance of multiple nucleoplasmic inclusions related to agroinfiltration superproduction were also found upon overexpression of the Arabidopsis protein coilin, a major structural component of Cajal bodies (Semashko et al. 2012).

To further investigate nucleocytoplasmic shuttling of the AMV CP, we wondered whether the protein also contained an NES. Leucine-rich NES are defined by LxxxLxxLxL motifs, although the spacer regions (x) can vary in number and, in some cases, other hydrophobic amino acids can substitute L residues (La Cour et al. 2003). The LRSLITVGL sequence between residues 204 and 212 of AMV CP represented a good candidate for a hydrophobic leucine-rich NES. In fact, deletion of this motif caused retention of the mutant $\mathrm{CP}$ inside the nucleus and, remarkably, mutant $\mathrm{CP}$ fluorescence was absent in the nucleolus of most nuclei. This observation may indicate that the sequence 204-LRSLITVGL-212 represents a second NoLS. However, taking into account that the N-terminal 5-KK AGGKAGK-13 sequence is sufficient for nucleolar targeting, we favor the hypothesis that the GFP:CPANES mutant would be involved in nucleolar retention. Nucleolar retention could be mediated by interaction of the protein with components of the nucleolus, as shown for the ORF3 protein of Groundnut rosette virus (GRV). The GRV ORF3 protein is an RNA-binding protein which contains, in addition to an N-terminal NoLS, a C-terminal leucine-rich NES involved in direct interaction with the nucleolar component fibrillarin (Kim et al. 2007a; Ryabov et al. 2004).

Early works reported that a peptide corresponding to the Nterminal 25 amino acids (aa) of AMV CP retained RNA-binding activity and was capable of initiating infection (Ansel- 
McKinney et al. 1996; Baer et al. 1994). This region of AMV $\mathrm{CP}$ contains $\mathrm{K}$ residues at positions $5,6,10,13$, and 16 and $\mathrm{R}$ at positions 17 and 25 (see Fig. 1B). However, only R17 was shown to be critical for binding of $\mathrm{CP}$ to the viral RNA, and replacement of $\mathrm{K}$ residues at positions 5, 6, 10, or 13 did not alter RNA-binding capacity of N-terminal peptides or fulllength CP (Ansel-McKinney et al. 1996; Yusibov and LoeschFries 1998). Indeed, we found that the CP(K5-13:A) mutant displayed higher RNA-binding affinity compared with wt CP despite the elimination of four positive charges around R17. Computational secondary structure analyses of the CP N-terminal region when changed to a more hydrophobic fragment in $\mathrm{CP}(\mathrm{K} 5-13: \mathrm{A})$ revealed that the critical RNA-binding R17 may be placed between two $\alpha$-helices in this mutant. The $5-\mathrm{K}$ KAGGKAGK-13 sequence may modulate RNA binding by AMV CP by assisting the generation of the appropriate folding surrounding R17. In the CP(K5-13:A) mutant, its new conformation would facilitate RNA binding by altering the binding affinity of the CP. Bacillus subtilis Ffh is a protein homolog component of the eukaryotic signal recognition particle implicated in targeting secretory proteins to the endoplasmic reticulum. This protein contains an RNA-binding domain consisting of a positively charged motif with RNA-binding activity surrounded by two hydrophobic segments. Both segments are folded into helix structures and, although any of them has RNA-binding properties, maintain a structural conformation necessary for RNA binding (Kurita et al. 1996). RNA binding of Escherichia coli RNaseIII is also facilitated by structural features, which are required to expose positively charged residues (Ævarsson et al. 1994). We also found that CP binds to two different binding sites present in the 3-NTR of the AMV RNA 3, as previously reported by Reusken and associates (1994). Moreover, our results suggest the presence of at least two different CP-binding sites in the 5-NTR of AMV RNA 3.

In vivo, R17 has been shown to be absolutely required for infection (Bol 2005), while the other positively charged residues contributed to the full activity of the CP. Deletion of the N-terminal 10 aa (which eliminates K 5 and 6) lowered viral replication approximately $25 \%$ in tobacco protoplasts (Yusibov and Loesch-Fries 1995) and blocked systemic spread of the virus in P12 plants (Tenllado and Bol 2000), whereas a change of K13 to A reduced viral accumulation approximately $80 \%$ in tobacco protoplasts (Yusibov and Loesch-Fries 1998). In agreement with these results, we found that R3 CP(K5-13:A)-infected P12 protoplasts displayed lower RNA 3 levels and higher levels of sgRNA 4 and CP compared with R3 CP in the earliest phases of the infection cycle (less than $24 \mathrm{hpi}$ ). At later infection stages (from 2 to $6 \mathrm{dpi}$ ), RNA 3 synthesis appeared to be severely impaired in R3 CP(K5-13:A)-infected P12 plants whereas sgRNA 4 and $\mathrm{CP}$ accumulation was similar to R3 CP.

Finally, our results revealed that the $\mathrm{CP}(\mathrm{K} 5-13$ :A) mutation caused reduced cell-to-cell movement. Consistent with previous results employing other AMV mutants (Sanchez-Navarro and Bol 2001; Tenllado and Bol 2000), the limited intercellular movement of R3 CP(K5-13:A) could be explained by its inability to self-interact and, consequently, to its failure to form stable viral particles. Our observation is in agreement with the model proposed by Kumar and associates (1997), in which both $\mathrm{N}$ - and C-terminal arms of $\mathrm{CP}$ would be required to stabilize $\mathrm{CP}-\mathrm{CP}$ interactions. In addition, abolished $\mathrm{CP}-\mathrm{CP}$ interaction in $\mathrm{Y} 2 \mathrm{H}$ was reported when $\mathrm{CP}$ mutants containing deletions of the first 10, 16, or 25 residues were assayed (Tenllado and Bol 2000). The inability of R3 CP(K5-13:A) to systemically invade the plant could also be explained by the failure to form viral particles, a prerequisite for AMV systemic movement.

An intriguing puzzle is the role of AMV CP nucleolar localization during infection. AMV CP is an integral component of the viral replicase subunit complex (Quadt et al. 1991). Recent studies have revealed that $\mathrm{CP}$ enhances replicase complex assembly and that binding of the CP to the viral 3-NTR helps to position the P2 subunit at the replication initiation site. However, increased CP levels at the replication sites inhibited replication and favored particle assembly (Reichert et al. 2007). Guogas and co-workers (2005) found that AMV replication was stimulated at low CP levels and strongly inhibited at high CP levels. The authors suggested that, as proposed for rubella virus (Chen and Icenogle 2004), CP concentration may represent a mechanism to regulate AMV replication. After entering a cell and particle disassembly, synthesis of viral RNAs leads to viral protein translation and their accumulation in the cytoplasm. According to the model that $\mathrm{CP}$ concentration may regulate replication and encapsidation, AMV may use the nucleus or nucleolus as a temporary storage site of CP to reduce excess of $\mathrm{CP}$ in the cytoplasm, which could downregulate viral replication. In the case of mutant $\mathrm{R} 3 \mathrm{CP}(\mathrm{K} 5,13: \mathrm{A})$, the protein is not transported to the nucleus, leading to high cytoplasmic $\mathrm{CP}$ accumulation. The cytoplasmic CP would stimulate sgRNA 4 synthesis (De Graaff et al. 1995) which, in turn, ensured elevated $\mathrm{CP}$ translation in the infected cells in a feedback regulation process. At the same time, these high $\mathrm{CP}$ levels would inhibit synthesis of genomic RNAs (RNA 3 in P12 plants).

The nucleolus is a multifunctional nuclear structure playing roles in various cellular processes, and sequestration or release of specific nucleolar or non-nucleolar proteins in the nucleolus is a mechanism to regulate specific cellular functions. (Emmott and Hiscox 2009). An example of sequestration of a viral protein into the nucleus to modulate its activity was reported for the suppressor protein P19 of Tomato bushy stunt virus. Relocation of P19 from the cytoplasm into the nucleus interferes with its silencing suppression activity (Canto et al. 2006). Other plant and animal viruses target viral proteins to the nucleolus to either prevent interference with cellular processes or to recruit nucleolar components important for infection (Greco 2009; Taliansky et al. 2010). In this sense, AMV $\mathrm{CP}$ nucleolar localization may modulate or recruit host nucleolar factors required to enhance AMV infection rather than merely representing a CP storage site. The observation that nuclear and nucleolar import signals mask RNA-binding properties of AMV CP, essential for viral replication and translation, supports a model in which viral expression is carefully modulated by a cytoplasmic/nuclear balance of $\mathrm{CP}$ accumulation.

Studies of RNA plant viruses have reported a nuclear or nucleolar step for several virus-encoded proteins but the function of this localization has only been shown for a few cases. One of the most extensively studied examples is GRV, which recruits fibrillarin to move systemically (Kim et al. 2007a and b). Nuclear inclusion protein a of Potato virus $A$ also interacts with fibrillarin and its nuclear or nucleolar localization is essential for different steps in the viral life cycle (Rajamaki and Valkonen 2009). In addition, the Grapevine fanleaf virus $2 \mathrm{~A}$ protein forms nuclear complexes with the $1 \mathrm{~A}$ protein and colocalizes with fibrillarin in specific subdomains within this compartment (M. C. Herranz and C. Ritzenthaler, unpublished results). Recruitment of host nucleolar factors has also been proposed to explain nucleolar localization of CP of PLRV and SPMV (Haupt et al. 2005; Qi et al. 2008). Experiments to identify nuclear or nucleolar factors interacting with AMV CP will provide further insight into nucleolar functions during AMV infection.

\section{MATERIALS AND METHODS}

\section{Plasmid construction.}

Plasmids R3 GFP and R3 GFP:CP were previously described by Sanchez-Navarro and associates (2001) and Sanchez- 
Navarro and Bol (2001) (referred to as GFP/MP/CP and GFP:CP/MP/CP, respectively). These plasmids express GFP or a GFP:CP fusion from an infectious AMV RNA 3 (Fig. 1A). Plasmid R3 CP (Fig. 4B) is the pALNcoP3 plasmid previously described in Neeleman and associates (1991).

Primers VP620 and asMP (Supplementary Table S1) were used to amplify a fragment containing the last 300 nucleotides of the C-terminal GFP and the first 17 nucleotides of the MP from plasmid R3 GFP:CP. This polymerase chain reaction (PCR) product contains unique Bsp1407I and XhoI restriction sites. The PCR fragment was cloned into the cloning vector pTZ57R/T (Fermentas, Vilnius, Lithuania), generating the pTZ/CtGFP:CP-NtMP plasmid (Supplementary Fig. S5). Sitedirected mutagenesis using the pTZ/CtGFP:CP-NtMP plasmid as template was performed to introduce the desired mutations into the CP ORF. Adjacent primers containing appropriate nucleotide changes were used to amplify pTZ/CtGFP:CPNtMP by inverse PCR. Full-length PCR products were phosphorylated with T4 PKA (Promega, Madison, WI, U.S.A.), religated using T4 DNA ligase (Promega), and transformed into $E$. coli $\mathrm{DH} 5 \alpha$ following the manufacturer's recommendations. Thus, plasmids pTZ/CtGFP:CPAN27-NtMP, pTZ/CtGFP: CP(K5-13:A)-NtMP, pTZ/CtGFP:CP(R25-K26:A)-NtMP, pTZ/ CtGFP:CP(R16-K17:A)-NtMP, and pTZ/CtGFP:CPN30-NtMP were obtained. pZT/GFP:CPAN27, pTZ/CtGFP:CPN30-NtMP, and $\mathrm{pTZ/CtGFP:CP} \triangle \mathrm{NES}-\mathrm{NtMP}$ clones were obtained using the same strategy but, here, primers were designed to delete the first 81 nucleotides of the $\mathrm{CP}$ or to introduce a stop codon after the first 90 nucleotides. Positive clones were confirmed by DNA sequencing. Through insertion of the Bsp1407I-XhoI fragment of the pTZ plasmids into the R3 GFP:CP plasmid cleaved with compatible Bsp1407I-XhoI, the AMV RNA 3 clones R3 GFP:CPAN27, R3 GFP:CP(K5-13:A), R3 GFP: CP(K16, R17:A), R3 GFP:CP(R24, K25:A), R3 GFP:CPN30, and R3 GFP:CPANES were obtained.

Inverse PCR using VP2040 to VP2041 primers and R3 CP wt or R3 GFP-MP-CP plasmids as templates was carried out to introduce the desired amino acid substitutions to obtain R3 CP(K5-13:A) and R3 GFP-MP-CP(K5-13:A) plasmids.

For $\mathrm{Y} 2 \mathrm{H}$ analyses, plasmids $\mathrm{BD}: \mathrm{imp} \alpha 1, \mathrm{AD}: \mathrm{CP}, \mathrm{BD}: \mathrm{CP}$, $\mathrm{AD}: \mathrm{CP}(\mathrm{K} 5-13: \mathrm{A})$, and $\mathrm{BD}: \mathrm{CP}(\mathrm{K} 5-13: \mathrm{A})$ were constructed. Arabidopsis imp- $\alpha 1$ (at3g06720) was amplified by reversetranscriptase PCR from total RNA with primers VP1993 to VP1994, and AMV CP wt and the CP(K5-13:A) mutant were amplified using VP625 to VP1196 or VP746 primers, respectively. PCR products were digested with NcoI-EcoRI or NdeI-EcoRI and inserted in pGADT7 or pGBKT7 plasmids (Clontech, Palo Alto, CA, U.S.A.) cleaved with compatible restriction sites.

For bimolecular fluorescence complementation analysis, Arabidopsis imp- $\alpha 1$, AMV CP, and CP(K5-13:A) were amplified using specific primers and cloned in $\mathrm{pDONR} / \mathrm{Zeo}$ vector (Gateway system; Invitrogen, Carlsbad, CA, U.S.A.). The Nterminus of the imp- $\alpha 1$ was fused to the $\mathrm{C}$-terminal fragment of the YFP in the destination vector p43CYFP (Gateway system; Invitrogen) to create CYFP-imp- $\alpha 1$. The N-terminus of the $\mathrm{CP}$ and $\mathrm{CP}(\mathrm{K} 5-13: \mathrm{A})$ were fused to the N-terminal YFP fragment in the destination vector p43NYFP (Gateway system; Invitrogen) to obtain NYFP-CP and NYFP-CP(K5-13:A).

In RNA-binding assays, pBluescript plasmids containing 5- or 3-NTR AMV between XbaI and PstI sites were used to transcribe plus-strand or DIG-labeled negative-strand RNAs. AMV CP and CP(K5-13:A) mutant sequences were amplified using VP2162-VP627 and VP2163-VP627 primers, respectively. PCR products were digested with BamHI-NotI and inserted into the bacterial expression plasmid pDUET (Novagen, Madison, WI, U.S.A.) to generate pDUET/CP and
pDUET/CP(K5-13:A). These clones contained the CP sequences after a sequence coding for a six-histidine tag.

\section{Protoplast and plant inoculation.}

N. tabacum P12 plants were grown in pots in a growth chamber at $24^{\circ} \mathrm{C}$ with a photoperiod of $16 \mathrm{~h}$ of light and $8 \mathrm{~h}$ of darkness. Plasmids R3 were linearized with PstI and transcribed with T7 RNA polymerase (Roche, Branchburg, NJ, U.S.A.) following the manufacturer's recommendations. Protoplasts $(2 \times$ $10^{6}$ ) prepared from P12 plants were inoculated with $10 \mu \mathrm{g}$ of R3 RNA transcripts by polyethylene glycol transfection (Loesch-Fries et al. 1985). P12 plants were mechanically inoculated with R3 RNA transcripts. Each RNA was inoculated on two plants using two leaves per plant and $10 \mu \mathrm{g}$ of the transcription mixture per leaf as inoculum.

\section{Northern and Western blots.}

Protoplasts and inoculated leaves were harvested at different times. Leaves were ground in liquid nitrogen with mortar and pestle. Total RNA was extracted from $2 \times 10^{6}$ protoplasts or $100 \mathrm{mg}$ of leaf material using Trizol Reagent (Sigma, St. Louis). RNAs were denatured by formaldehyde treatment and analyzed by Northern blot hybridization as described previously (Sambrook et al. 1989). RNAs were visualized on blots using DIG-labeled riboprobes corresponding to the AMV CP gene (Dig-CP). Hybridization and DIG detection procedures were carried out as previously described (Pallas et al. 1998).

Total proteins were extracted from $1 \times 10^{6}$ protoplasts or 50 $\mathrm{mg}$ of leaf tissue. Samples were homogenized with $100 \mu \mathrm{l}$ of Laemmli buffer (Laemmli 1970) and boiled $3 \mathrm{~min}$, and $25 \mu \mathrm{l}$ of extracts were resolved in a $12 \%$ sodium dodecyl sulfate polyacrylamide gel electrophoresis. Gels were electrotransferred to polyvinylidene diflouride membranes (Amersham, Tokyo) following the manufacturer's recommendations. Detection of hemagglutinin (HA), myc, or histone (His) fusion proteins (epitopes expressed from constructs engineered in plasmids pGBKT7, pGADT7, and pDUET, respectively) was carried out with commercial primary antibodies (myc and His from Roche and HA from Sigma), anti-mouse or anti-rabbit horseradish peroxidase-labeled secondary antibodies, and ECL detection reagent (Amersham). In all cases, reactions were carried out following the manufacturer's recommendations. AMV CP was detected using a specific antiserum (Van der Vossen et al. 1996).

\section{Y2H system.}

$\mathrm{Y} 2 \mathrm{H}$ analyses were carried out using the Matchmaker Gal4 Two-Hybrid System 3 (Clontech). The yeast reporter strain AH109 (Clontech) was transformed following the manufacturer's recommendations. Transformants were selected after incubation at $28^{\circ} \mathrm{C}$ for 3 days on minimal synthetic dropout medium lacking leucine and tryptophan. Protein interactions were detected under the same growth conditions and medium but lacking also adenine and histidine.

\section{Bimolecular fluorescence complementation.}

Fusion proteins were transformed into Agrobacterium C58 cells. Pairs of cultures carrying specific fusion proteins were mixed, at an optical density of 0.2 each, in infiltration solution

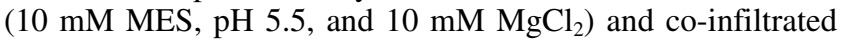
into $N$. benthamiana leaves. Laser-scanning confocal images were taken $48 \mathrm{~h}$ after agroinfiltration.

\section{Protein-RNA-binding studies.}

E. coli (DE3) BL21 strains (Novagen) transformed with $\mathrm{pDUET} / \mathrm{CP}$ and $\mathrm{pDUET} / \mathrm{CP}\left(\mathrm{K} 5-13\right.$ :A) were grown at $28^{\circ} \mathrm{C}$ $\mathrm{o} / \mathrm{n}$ and induced with $0.2 \mathrm{mM}$ isopropyl-thio-galactopyra- 
noside for $5 \mathrm{~h}$. Cells were harvested by centrifugation; resuspended in $25 \mathrm{mM}$ Tris- $\mathrm{HCl}(\mathrm{pH} 8), 250 \mathrm{mM} \mathrm{NaCl}, 5 \%$ glycerol, and $1 \times$ protease inhibitor cocktail (Boerhinger, Mannheim, Germany); and disrupted by sonication. Triton X-100 (0.5\%) was added to the lysate and, after centrifugation $(25,000 \times g$, $20 \mathrm{~min}$ at $4^{\circ} \mathrm{C}$ ), the supernatant was used for purification of the His six-tagged protein using a nickel resin (Novagen).

Protein-RNA-binding studies were performed by EMSA as previously described (Aparicio et al. 2003). Briefly, $5 \mathrm{ng}$ of plus-strand 5- or 3-NTR of AMV RNA 3 RNA transcripts was heated for $5 \mathrm{~min}$ at $85^{\circ} \mathrm{C}$ and cooled at room temperature for 15 min. Different amounts of purified CP or CP(K5-13:A) were added and incubated for $30 \mathrm{~min}$ at $4{ }^{\circ} \mathrm{C}$ in a $10-\mu l$ final volume of phosphate-EDTA buffer $(10 \mathrm{mM}$ Na-phosphate buffer [pH 7.0], $1 \mathrm{mM}$ EDTA, and 5 units of HRPI RNase inhibitor). Following incubations, the samples were separated through $1.2 \%$ agarose. RNAs were electrotransferred to positively charged nylon membranes (Roche) in Tris-acetateEDTA at $40 \mathrm{~V}$ for $2 \mathrm{~h}$ at $4^{\circ} \mathrm{C}$. Hybridization and detection with 5- and 3-NTR DIG-labeled riboprobes was conducted as described above.

\section{ACKNOWLEDGMENTS}

M. C. Herranz and F. Aparicio were recipients of a contract from the Juan de la Cierva and the Ramón y Cajal (RYC-2010-06169) programs of the Ministerio de Educación y Ciencia of Spain. This work was supported by grant BIO2011-25018 from the Spanish granting agency DGICYT and the Prometeo Program GV2011/003 from the Generalitat Valenciana. We thank A. Niehl for the critical reading of the manuscript, J. A. SánchezNavarro for providing R3 GFP and R3 GFP:CP constructs, and L. Corachan for her excellent technical assistance.

\section{LITERATURE CITED}

Ævarsson, A., Brazhnikov, E., Garber, M., Zherltonosova, J., Chirgadze, Y., Al-Karadaghi, S., Suensson, L. A., and Liljas, A. 1994. Three-dimensional structure of the ribosomal translocase: Elongation factor $\mathrm{G}$ from Thermus thermophilus. EMBO (Eur. Mol. Biol. Organ.) J. 13:36693677.

Ansel-McKinney, P., Scott, S. W., Swanson, M., Ge, X., and Gehrke, L. 1996. A plant viral coat protein RNA binding consensus sequence contains a crucial arginine. EMBO (Eur. Mol. Biol. Organ.) J. 15:50775084.

Aparicio, F., Vilar, M., Perez-Paya, E., and Pallas, V. 2003. The coat protein of Prunus necrotic ringspot virus specifically binds to and regulates the conformation of its genomic RNA. Virology 313:213-223.

Aparicio, F., Sánchez-Navarro, J., and Pallás, V. 2006. In vitro and in vivo mapping of the Prunus necrotic ringspot virus coat protein $\mathrm{C}$-terminal dimerization domain by bimolecular fluorescence complementation. J. Gen. Virol. 87:1745-1750.

Asurmendi, S., Berg, R. H., Koo, J. C., and Beachy, R. N. 2004. Coat protein regulates formation of replication complexes during Tobacco mosaic virus infection. Proc. Natl. Acad. Sci. U.S.A. 101:1415-1420.

Baer, M., Houser, F., Loesch-Fries, L. S., and Gehrke, L. 1994. Specific RNA binding by amino-terminal peptides of alfalfa mosaic virus coat protein. EMBO (Eur. Mol. Biol. Organ.) J. 13:727-735.

Ballas, N., and Citovsky, V. 1997. Nuclear localization signal binding proteins from Arabidopsis mediates nuclear import of AgrobacteriumVirD2 protein. Proc. Natl. Acad. Sci. U.S.A. 94:10723-10728.

Bamunusinghe, D., Seo, J.-K., and Rao, A. L. N. 2011. Subcellular localization and rearrangement of endoplasmic reticulum by Brome mosaic virus capsid protein. J. Virol. 85:2953-2963.

Bhattacharjee, S., Lee, L.-Y., Oltmanns, H., Cao, H., Veena, Cuperus, J., and Stanton, B. G. 2008. IMPa-4, an Arabidopsis importin a isoform, is preferentially involved in agrobacterium-mediated plant transformation. Plant Cell 20:2661-2680.

Bol, J. F. 2005. Replication of alfamo- and ilarviruses: Role of the coat protein. Annu. Rev. Phytopathol. 43:39-62.

Boyne, J.-R., and Whitehouse, A. 2006. Nucleolar trafficking is essential for nuclear export of intronless herpesvirus mRNA. Proc. Natl. Acad. Sci. U.S.A. 103:15190-15195.

Brigneti, G., Voinnet, O., Li, W. X., Ji, L. H., Ding, S. W., and Baulcombe, D. C. 1998. Viral pathogenicity determinants are suppressors of transgene silencing in Nicotiana benthamiana. EMBO (Eur. Mol. Biol. Organ.) J. 17:6739-6746.

Canto, T., Uhrig, J. F., Swanson, M., Wright, K. M., and MacFarlane, S. A. 2006. Translocation of Tomato bushy stunt virus P19 protein into the nucleus by ALY proteins compromises its silencing suppressor activity. J. Virol. 80:9064-9072.

Chen, M. H., and Icenogle, J. P. 2004. Rubella virus capsid protein modulates viral genome replication and virus infectivity. J. Virol. 78:43144322

Crivelli, G., Ciuffo, M., Genre, A., Masenga, V., and Turina, M. 2011 Reverse genetic analysis of ourmiaviruses reveals the nucleolar localization of the coat protein in Nicotiana benthamiana and unusual requirements for virion formation. J. Virol. 85:5091-5104.

Csorba, T, Pantaleo, V., and Burgyan, J. 2009. RNA silencing: An antiviral mechanism. Adv. Virus Res. 75:53-71.

De Graaff, M., Man In T'Veld, M. R., and Jaspars, E. M. 1995. In vitro evidence that the coat protein of alfalfa mosaic virus plays a direct role in the regulation of plus and minus RNA synthesis: Implications for the life cycle of alfalfa mosaic virus. Virology 208:583-589.

Emmott, E., and Hiscox, J. A. 2009. Nucleolar targeting: The hub of the matter. EMBO (Eur. Mol. Biol. Organ.) Rep. 10:231-238.

Greco, A. 2009. Involvement of the nucleolus in replication of human viruses. Rev. Med. Virol. 19:201-214.

Guogas, L. M., Laforest, S. M., and Gehrke, L. 2005. Coat protein activation of Alfalfa mosaic virus replication is concentration dependent. J. Virol. 79:5752-5761.

Haupt, S., Stroganova, T., Ryabov, E., Kim, S. H., Fraser, G., Duncan, G., Mayo, M. A., Barker, H., and Taliansky, M. 2005. Nucleolar localization of Potato leafroll virus capsid proteins. J. Gen. Virol. 86:28912896.

He, S., Huang, K., Zhang, X., Yu, X., Huang, P., and An, C. 2011. The LSD1-type zinc finger motifs of Pisum sativa lsd1 are a novel nuclear localization signal and interact with importin alpha. PLoS One 6:e22131. Published online.

Hübner, S., Smith, H. M. S., Hu, W., Chan, C. K., Rihs, H.-P., Paschali, B. M., Raikhel, N. V., and Jans, D. A. 1999. Plant importin a binds nuclear localization sequences with high affinity and can mediate nuclear import independent of importin b. J. Biol. Chem. 274:22610-22617.

Kao, C. C., Ni, P., Hema, M., Huang, X., and Dragnea, B. 2011. The coat protein leads the way: An update on basic and applied studies with the Brome mosaic virus coat protein. Mol. Plant Pathol. 678:403-412.

Kim, S. H., MacFarlane, S., Kalinina, N. O., Rakitina, D., Ryabov, E.V., Gillespie, T., Haupt, S., Brown, J. W. S., and Taliansky, M. 2007a. Interaction of a plant virus-encoded protein with the major nucleolar protein fibrillarin is required for systemic virus infection. Proc. Nat. Acad. Sci. U.S.A. 104:11115-11120.

Kim, S. H., Ryabov, E. V., Kalinina, N. O., Rakitina, D. V., Gillespie, T., MacFarlane, S., Haupt, S., Brown, J. W. S., and Taliansky, M. 2007b. Cajal bodies and the nucleolus are required for a plant virus systemic infection. EMBO (Eur. Mol. Biol. Organ.) J. 26:2169-2179.

Krab, I. M., Caldwell, C., Gallie, R. D., and Bol, J. F. 2005. Coat protein enhances translational efficiency of Alfalfa mosaic virus RNAs and interacts with the eIF4G component of initiation factor eIF4F. J. Gen. Virol. 86:1841-1849.

Krichevsky, A., Kozlovsky, S. V., Gafni, Y., and Citovsky, V. 2006. Nuclear import and export of plant virus proteins and genomes. Mol. Plant Pathol. 7:131-146.

Kumar, A., Reddy, V. S., Yusibov, V., Chipman, P. R., Hata, Y., Fita, I., Fukuyama, K., Rossmann, M. G., Loesch-Fries, L. S., Baker, T. S., and Johnson, J. E. 1997. The structure of alfalfa mosaic virus capsid protein assembled as a T 51 icosahedral particle at 4.0- $\AA$ resolution. J. Virol. 71:7911-7916.

Kurita, K., Honda, K., Suzuma, S., Takamatsu, S., Nakamura, K., and Yamane, K. 1996. Identification of a region of Bacillus subtilis Ffh, a homologue of mammalian SRP54 protein, that is essential for binding to small cytoplasmic RNA. J. Biol. Chem. 271:13140-13146.

La Cour, T., Gupta, R., Rapacki, K., Skriver, K., Poulsen, F. M., and Brunak, S. 2003. NESbase version 1.0: A database of nuclear export signals. Nucleic Acids Res. 31:393-396.

Laemmli, U. K. 1970. Cleavage of structural protein during the assembly of the head of bacteriophage T4. Nature 227:680-685.

Loesch-Fries, L. S., Halk, E. L., Nelson, S. E., and Krahn, K. J. 1985. Human leukocyte interferon does not inhibit alfalfa mosaic virus in protoplasts or tobacco tissue. Virology 143:626-629.

Neeleman, L., van der Kuil, A. C., and Bol, J. F. 1991. Role of alfalfa mosaic virus coat protein gene in symptom formation. Virology 181:687698.

Neeleman, L., Linthorst, H. J. M., and Bol, J. F. 2004. Efficient translation of alfamovirus RNAs requires the binding of coat protein dimers to the $3^{\prime}$ termini of the viral RNAs. J. Gen. Virol. 85:231-240. 
Pallas, V., and Garcia, J. A. 2011. How do plant viruses induce disease? Interactions and interference with host components. J. Gen Virol. 92:2691-2705.

Pallas, V., Mas, P., and Sanchez-Navarro, J. A. 1998. Detection of plant RNA viruses by nonisotopic dot-blot hybridization. Methods Mol. Biol. 81:461-468.

Qi, D., Omarov, R. T., and Scholthof, K. B. G. 2008. The complex subcellular distribution of satellite panicum mosaic virus capsid protein reflects its multifunctional role during infection. Virology 376:154-164.

Quadt R., Rosdorff H. J. M., Hunt T. W., and Jaspars, E. M. J. 1991. Analysis of the protein composition of alfalfa mosaic virus RNA-dependent RNA polymerase. Virology 182:309-315.

Rajamaki, M. L., and Valkonen, J. P. T. 2009. Control of nuclear and nucleolar localization of nuclear inclusion protein a of picorna-like Potato virus A in Nicotiana species. Plant Cell 21:2485-2502.

Rao, A. L., and Grantham G. L. 1996. Molecular studies on bromovirus capsid protein. II. Functional analysis of the amino-terminal argininerich motif and its role in encapsidation, movement, and pathology. Virology 226:294-305.

Reichert, V. L., Choi, M., Petrillo, J. E., and Gehrke, L. 2007. Alfalfa mosaic virus coat protein bridges RNA and RNA-dependent RNA polymerase in vitro. Virology 364:214-226.

Reusken, C. B. E. M., Neeleman, L., and Bol, J. F. 1994. The 3'-untranslated region of alfalfa mosaic virus RNA 3 contains at least two independent binding sites for viral coat protein. Nucleic Acids Res. 22:1346-1353.

Roy, A., Kucukural, A., and Zhang, Y. 2010. I-TASSER: A unified platform for automated protein structure and function prediction. Nat. Protocols 5:725-738.

Ryabov, E. V., Kim, S. H., and Taliansky, M. E. 2004. Identification of a nuclear localization signal and nuclear export signal of the umbraviral long-distance RNA movement protein. J. Gen. Virol. 85:1329-1333.

Sambrook, J., Fritsch, E. F., and Maniatis, T. 1989. Molecular Cloning: A Laboratory Manual. Cold Spring Harbor Laboratory Press, Cold Spring Harbor, NY, U.S.A.

Sanchez-Navarro, J. A., and Bol, J. F. 2001. Role of the Alfalfa mosaic virus movement protein and coat protein in virus transport. Mol. PlantMicrobe Interact. 14:1051-1062.

Sanchez-Navarro, J. A., and Pallas, V. 1997. Evolutionary relationships in the ilarviruses: Nucleotide sequence of prunus necrotic ringspot virus RNA 3. Arch. Virol. 142:749-763.

Sanchez-Navarro, J. A., Miglino, R., Ragozzino, A., and Bol, J. F. 2001. Engineering of Alfalfa mosaic virus RNA 3 into an expression vector. Arch. Virol. 146:923-939.

Scholthof, H. B. 2005. Plant virus transport: Motions of functional equivalence. Trends Plant Sci. 10:376-382.

Semashko, M. A., Rakitina, D. V., González, I., Canto, T., Kalinina, N. O., and Taliansky, M. E. 2012. Movement protein of hordeivirus interacts in vitro and in vivo with coilin, a major structural protein of Cajal bodies. Dokl. Biochem. Biophysics. 44:57-60.

Sharma, P., and Ikegami, M. 2009. Characterization of signals that dictate nuclear/nucleolar and cytoplasmic shuttling of the capsid protein of Tomato leaf curl Java virus associated with DNAb satellite. Virus Res. 144:145-153

Taliansky, M. E., Brown, J. W. S., Rajamaki, M. L., Valkonen, J. P. T., and Kalinina, N. O. 2010. Involvement of the plant nucleolus in virus and viroid infections: Parallels with animal pathosystems. Adv. Virus Res. 77:119-158.

Taschner, P. E., Van der Kuyl, A. C., Neeleman, L., and Bol, J. F. 1991 Replication of an incomplete alfalfa mosaic virus genome in plants transformed with viral replicase genes. Virology 181:445-450.

Tenllado, F., and Bol, J. F. 2000. Genetic dissection of the multiple functions of Alfalfa mosaic virus coat protein in viral RNA replication, encapsidation, and movement. Virology 268:29-40.

Van der Vossen E. A. G., Neeleman L., and Bol, J. F. 1994. Early and late functions of alfalfa mosaic virus coat protein can be mutated separately. Virology 202:891-903.

Van der Vossen, E. A. G., Reusken, B. E. M., and Bol, J. F. 1996. Cis-preferential stimulation of alfalfa mosaic virus RNA 3 accumulation by the viral coat protein a. Virology 220:163-70.

Vanpeltheerschap, H., Verbeek, H., Slot, J. W., and Vanvlotendoting, L. 1987. The location of coat protein and viral RNAs of alfalfa mosaicvirus in infected tobacco leaves and protoplasts. Virology 160:297-300.

Wang, Y., Tzfira, T., Gaba, V., Citovsky, V., Palukaitis, P., and Gal-On, A. 2004. Functional analysis of the Cucumber mosaic virus $2 \mathrm{~b}$ protein Pathogenicity and nuclear localization. J. Gen. Virol. 85:3135-3147.

Yusibov, V. M., and Loesch-Fries, L. S. 1995. N-terminal basic amino acids of alfalfa mosaic virus coat protein involved in the initiation of infection. Virology 208:405-407.

Yusibov, V., and Loesch-Fries, L. S. 1998. Functional significance of three basic $n$ terminal amino acids of alfalfa mosaic virus coat protein. Virology $242: 1-5$.

Zhang, Y. 2008. I-TASSER server for protein 3D structure prediction. BMC Bioinf. 9:40.

Zhang, Y. J., Zhang, X. F., Niu, S. F., Han, C. G., Yu, J. L., and Li, D. W. 2011. Nuclear localization of Beet black scorch virus capsid protein and its interaction with importin alpha. Virus Res. 155:307-315.

\section{AUTHOR-RECOMMENDED INTERNET RESOURCES}

I-TASSER protein structure and function predictions server: zhanglab.ccmb.med.umich.edu/I-TASSER

National Institutes of Health ImageJ website: rsbweb.nih.gov/ij 